\title{
Trauma and Posttraumatic Stress in Unaccompanied Young Refugees During Their Flight: A Longitudinal Cross-Country Study
}

Elisa Pfeiffer ( $\sim$ elisa.pfeiffer@uniklinik-ulm.de)

Ulm University

Malte Behrendt

Ghent University

Sarah Adeyinka

Ghent University

Ines Devlieger

Ghent University

Marina Rota

Ghent University

Océane Uzureau

Ghent University

Floor Verhaeghe

Ghent University

Ine Lietaert

Ghent University

Ilse Derluyn

Ghent University

\section{Research Article}

Keywords: Refugee, Youth, Trauma, PTSD, Flight, Daily Stressor

Posted Date: December 21st, 2021

DOI: https://doi.org/10.21203/rs.3.rs-1174857/v1

License: (c) (i) This work is licensed under a Creative Commons Attribution 4.0 International License.

Read Full License 


\section{Abstract}

Background: Unaccompanied young refugees (UYRs) constitute an especially vulnerable population who report high rates of trauma and mental health problems. There is a significant gap in the literature on trauma and symptoms of posttraumatic stress disorder (PTSD) in UYRs who are still on the move and live in precarious circumstances such as refugee camps. This study therefore aimed at investigating preand peri-migration trauma of UYRs, longitudinal trajectories of PTSD, and the impact of gender, trauma, and daily stressors on PTSD over time.

Methods: This longitudinal, mixed-method, and multi-country study was conducted in various settings (e.g. refugee camps) across nine European countries. A representative and heterogeneous sample of $N=$ 187 UYRs (78.4\% male) from 29 different countries was assessed via interviews at 3 time-points during a period of 27 months. Data was analyzed via growth curve modelling.

Results: Prevalence rates of traumatic experiences ranged between 29.5-91.9\%. PTSD scores were high but significantly decreased over time $(b=-0.98 ; p=.004)$. Females reported higher PTSD compared with males at baseline $(p=.002)$, but gender did not influence the longitudinal trajectory of PTSD. Premigration trauma had a significant effect on PTSD at baseline $(b=0.48 ; p=.042)$. More daily stressors resulted in higher PTSD across time $(b=0.13-0.26 ; p \leq .001)$.

Conclusions: The number of traumatic events pre- and peri- migration, daily stressors and PTSD in this heterogeneous sample are to say the least alarming. Humanitarian and political assistance is urgently needed to curb the oftentimes life-threatening conditions UYRs face during their migration.

\section{Background}

Between 2017 and 2020 alone, more than 275 million people worldwide had been forcibly displaced for reasons ranging from armed conflict and persecution to economic pressure and natural disasters (1). Estimates suggest that $30-43 \%$ of all refugees worldwide are below 18 years old (2). Unaccompanied young people resettling as refugees (UYRs) who are not protected by their parent(s) or guardian(s) but instead travel by themselves constitute an especially vulnerable population. They face the atrocities of conflict-related violence and the numerous hardships of flight during crucial phases of their physical, emotional, social, and cognitive development (3). As most studies investigating trauma and stressors during migration are conducted post-migration with young refugees who are settling down in several Northern European countries (4-7), there is, however, a significant lack of prospective epidemiological quantitative and longitudinal evidence on their specific traumatic experiences pre-, and peri-migration.

Recent reviews and meta-analyses on mental disorders among UYRs revealed that $19-53 \%$ report PTSD, $10-33 \%$ depression, and $9-32 \%$ anxiety $(8,9)$; which are significantly higher prevalence rates compared to accompanied refugees and European samples (10). The few existing longitudinal studies suggest a chronic trajectory of mental health problems in refugee minors $(6,11)$. 
Trauma-related mental health problems do not result from a single cause or stressor, but from complex causal chains (12). Among several individual risk factors, such as female gender $(3,11)$, strong evidence suggests that cumulative exposure to traumatic events (often referred to as "trauma load") is associated with subsequent psychological disturbances, such as PTSD, in this population (11). However, in their longitudinal study with re-settled refugee minors in Belgium, Vervliet et al. (6) found that next to trauma load, daily stressors, such as insufficient medical care or social support, have a significant impact on mental health. Again, these known risk factors for the development of PTSD have not been investigated with refugees who are still on the move.

During their travels, UYRs often face harsh conditions, forced detention, and violence in transit countries. The "transit" condition is a situation whose effects, due to several practical difficulties linked with conducting research on migrants during their journey, are generally still relatively unknown. Refugees who want to reach Northern Europe mostly cross the Mediterranean sea and enter the European Union in Spain, Italy, Greece, or Malta (13). Research on (mental) health and experiences in these transit countries is, however, limited. Preliminary studies of transiting (adult) refugees in Greece (14) or Italy (15) report high trauma load and prevalence rates of mental health disorders such as PTSD, depression, substance abuse and anxiety. Yet, none of the studies investigated UYRs in particular. Moreover, most studies report prevalence rates of single countries and lack comparisons between different settlement and transit countries.

Regarding study setting, the growing body of research on mental health of UYRs has several crucial limitations which substantially hamper the field's understanding of their health in the context of migration. So far, very little studies were conducted with UYRs living in refugee camps or detention centers, but instead in asylum centers $(16)$, psychiatric hospitals $(5,17)$, or child welfare programs $(18)$. However, daily life in refugee camps and detention centers along the borders constitute an especially challenging situation with a high number of daily stressors as there is oftentimes minimal access to shelter, food, water, education, privacy, or protection. In sum, there has been no systematic research to fully capture traumatic experiences and PTSD in UYRs during their flight. The discrepancy between the importance of the topic and the dearth of data is striking.

This longitudinal follow-up study therefore aimed at filling these gaps, since the study was conducted with UYRs in various contexts (refugee camps, detention centers, housing units, informal settings), in different cities and regions in nine different European countries, and over a time period of almost two years.

\section{Aims of this study}

This study aimed at (A) investigating traumatic experiences reported by UYRs on the move at different time points of their migration, (B) to investigate longitudinal trajectories of PTSD symptoms in UYRs on the move, and $(\mathrm{C})$ to assess the impact of gender, traumatic experiences, and daily stressors on PTSD in UYRs on the move. 


\section{Methods}

This study was part of the European Research Council [HORIZON project number: 714222] funded mixedmethod multi-site and multi-country (Belgium, Italy, Greece, Libya) CHILDMOVE project. The project aimed to increase knowledge about the impact of experiences occurring during the flight on the psychological wellbeing of UYRs in relation to the impact of past traumatic experiences in the home countries and to daily stressors in the current country of stay.

\section{Participants}

The study sample consisted of $\mathrm{N}=187$ participants $\left(M_{\text {age }}=16.78 ; S D_{\text {age }}=2.36 ; 21.6 \%\right.$ female) with $n=$ $64(34.2 \%)$ in Italy, $n=79(42.2 \%)$ in Belgium and $n=44$ (23.5\%) in Greece at baseline. Demographic information of the entire study sample and subsamples per country is presented in Table 1.

Table 1 Sociodemographic characteristics of participants across country at baseline (M1) 


\begin{tabular}{|c|c|c|c|c|}
\hline & \multicolumn{4}{|c|}{ Subsamples } \\
\hline & Italy & Belgium & Greece & Total \\
\hline & $\mathrm{n}=64$ & $\mathrm{n}=79$ & $\mathrm{n}=44$ & $\mathrm{n}=187$ \\
\hline \multicolumn{5}{|l|}{ Gender } \\
\hline male n (\%) & $32(50.8)$ & $72(91.1)$ & $41(95.3)$ & $145(78.4)$ \\
\hline female n (\%) & $31(49.2)$ & $7(8.9)$ & $2(4.7)$ & $40(21.6)$ \\
\hline Age $M(S D) ;$ range & $\begin{array}{l}17.97 \\
(3.17) ; 13- \\
25\end{array}$ & $\begin{array}{l}15.87 \\
(1.23) ; 13- \\
20\end{array}$ & $\begin{array}{l}16.23 \\
(1.24) ; 13- \\
19\end{array}$ & $\begin{array}{l}16.78 \\
(2.36) ; 13- \\
25\end{array}$ \\
\hline \multicolumn{5}{|c|}{ Country of origin n (\%) } \\
\hline Afghanistan & - & $22(27.8)$ & $11(26.2)$ & $33(18.0)$ \\
\hline Albania & - & $5(6.3)$ & - & $5(2.7)$ \\
\hline Algeria & - & $1(1.3)$ & - & $1(0.5)$ \\
\hline Cameroon & - & $1(1.3)$ & - & $1(0.5)$ \\
\hline Chad & - & $4(5.1)$ & - & $4(2.2)$ \\
\hline Congo, Dem. Rep. & - & $4(5.1)$ & - & $4(2.2)$ \\
\hline Cote d'Ivoire & $5(8.1)$ & $1(1.3)$ & - & $6(3.3)$ \\
\hline Egypt & - & $1(1.3)$ & - & $1(0.5)$ \\
\hline Eritrea & $7(11.3)$ & $14(17.7)$ & - & $21(11.5)$ \\
\hline Ethiopia & $4(6.5)$ & -- & - & $4(2.2)$ \\
\hline Gabon & $1(1.6)$ & - & - & $1(0.5)$ \\
\hline The Gambia & $3(4.8)$ & -- & - & $3(1.6)$ \\
\hline Guinea & $2(3.2)$ & $10(12.7)$ & - & $12(6.6)$ \\
\hline Iran & - & - & $1(2.4)$ & $1(0.5)$ \\
\hline Iraq & - & $3(3.9)$ & $3(7.1)$ & $5(2.7)$ \\
\hline Lebanon & - & $2(2.5)$ & - & $2(1.1)$ \\
\hline Libya & $3(4.8)$ & -- & - & $3(1.6)$ \\
\hline Mali & $2(3.2)$ & $1(1.3)$ & - & $3(1.6)$ \\
\hline Morocco & - & $1(1.3)$ & $1(2.4)$ & $2(1.1)$ \\
\hline Nigeria & 26 (41.9) & - & - & $26(14.2)$ \\
\hline
\end{tabular}




\begin{tabular}{|c|c|c|c|c|}
\hline Pakistan & - & - & $20(47.6)$ & $20(10.9)$ \\
\hline Senegal & $1(1.6)$ & $1(1.3)$ & - & $2(1.1)$ \\
\hline Serbia & - & $1(1.3)$ & - & $1(0.5)$ \\
\hline Sierra Leone & - & - & $1(2.4)$ & $1(0.5)$ \\
\hline Somalia & $2(3.2)$ & $1(1.3)$ & - & $3(1.6)$ \\
\hline Sudan & $2(3.2)$ & - & - & $2(1.1)$ \\
\hline Syria & - & $4(5.1)$ & $5(11.9)$ & $9(4.9)$ \\
\hline Tunisia & $4(6.5)$ & $1(1.3)$ & - & $5(2.7)$ \\
\hline South Sudan & - & $1(1.3)$ & - & $1(0.5)$ \\
\hline $\begin{array}{l}\text { Time since left home country (in months) } \\
\text { M, SD (range) }\end{array}$ & $\begin{array}{l}16.66,9.38 \\
(2-49)\end{array}$ & $\begin{array}{l}15.5,13.56 \\
(0-72)\end{array}$ & $\begin{array}{l}17.75,1.30 \\
(2-48)\end{array}$ & $\begin{array}{l}\text { 16.39, } \\
12.15(0- \\
72)\end{array}$ \\
\hline \multicolumn{5}{|l|}{ Contact with parents } \\
\hline Yes n (\%) & $31(77.5)$ & $23(35.9)$ & $25(65.5)$ & $79(55.6)$ \\
\hline \multicolumn{5}{|l|}{ Living situation $\mathrm{n}(\%)$} \\
\hline Reception center for minors only & $11(17.2)$ & $79(100)$ & - & $90(48.4)$ \\
\hline $\begin{array}{l}\text { Collective reception center for adults and } \\
\text { minors - no separation }\end{array}$ & $2(3.1)$ & - & - & $2(1.1)$ \\
\hline $\begin{array}{l}\text { Collective reception center for adults and } \\
\text { minors }\end{array}$ & $16(25)$ & - & - & $16(8.6)$ \\
\hline \multicolumn{5}{|l|}{ - minors separated } \\
\hline Detention center & - & - & $12(27.9)$ & $12(6.5)$ \\
\hline House, studio or flat & $26(40.6)$ & - & - & $26(14)$ \\
\hline Informal camp & $9(14.1)$ & - & - & $9(4.8)$ \\
\hline Shelter for unaccompanied minors & - & - & $31(72.1)$ & $31(16.7)$ \\
\hline \multicolumn{5}{|l|}{ Asylum status n (\%) } \\
\hline Procedure in process & $12(18.8)$ & $79(100)$ & $22(53.7)$ & $113(61.4)$ \\
\hline $\begin{array}{l}\text { Granted family reunification -waiting for } \\
\text { transfer }\end{array}$ & $2(3.1)$ & - & $2(4.9)$ & $4(12.5)$ \\
\hline Temporary documents -less than 1 year & $23(35.9)$ & - & - & $23(12.5)$ \\
\hline Temporary documents -less than 2 years & $1(1.6)$ & - & - & $1(0.5)$ \\
\hline Definite residence permit & $3(4.7)$ & - & $2(4.9)$ & $5(2.7)$ \\
\hline
\end{tabular}




\section{Recruitment, procedure and setting}

The recruitments and first assessments in Greece were conducted in centers for UYRs, a detention center, and a refugee camp (Reception and Identification Centre) in Thessaloniki, Samos and Athens. The sample of participants who were recruited in Italy is a combination of two study samples: One sample of participants was recruited in three centers for refugees and victims of trafficking in Campagnia, Piemonte, and Sicily, while the other sample of participants was recruited in a first reception centre located in Sicily, and transit camps, and informal settlements in Lazio, and Imperia regions. In the Belgian context, the recruitment and first assessments were conducted in two reception centers for newly arrived UYRs in the Brussels region. If feasible, the researchers engaged in participant observation and spent time with the young people to build rapport before asking them whether they wanted to participate. We aimed at making the samples representative of the population regarding demographic composition (i.e., gender and nationality) in each context.

Participants were assessed at three measurement time points: Baseline (M1), a follow-up (M2) after approximately 8 months $(M=8.0, S D=2.4$, range $=5-17)$ and another follow-up (M3) after approximately 21 months $(M=20.5, S D=3.0$, range $=12-27)$. For number of missing data please see SP1. After $M 1$ the researchers invited the participants to exchange contact details and offered to stay in touch with the participants via phone calls, messages or social media. Via these contact details, participants were invited to follow-up assessments and researchers would travel to their current location. Follow-up assessments took place in Greece, Italy, Belgium, Germany, Netherlands, UK, Switzerland, Spain, and Malta. The interviews were conducted between October 2017 and October 2020. All measures were translated into 13 languages and were assessed by trained assessors (authors MB, SA, OU, MR) via (semi-)structured interviews. Interpreters and cultural mediators were employed if the bi-/multi-lingual researcher and participant did not speak a common language and according to participants' preferences.

\section{Ethics committee approval}

All participants and, if already appointed, their legal guardians in the case of minors gave their informed written consent before being enrolled in the study. The study protocol was approved by the institutional review board (IRB) at Ghent University (\#2017-23-Ine Lietaert).

\section{Measures}

\section{Choice of primary measure}

The "Reactions of Adolescents to Traumatic Stress questionnaire (RATS)" (19) was chosen as primary measure for this study as PTSD is the most prevalent reported mental health disorder in UYRs. The RATS 
is a multicultural self-report measure assessing the prevalence of posttraumatic stress symptoms according to DSM-IV criteria. The measure has been widely used with youth and UYRs in particular. For the use with UYRs, the measure has been translated and backtranslated into 19 different languages. For this study we used an ICD-11 conceptualization (five items intrusion, one item avoidance, two items hyperarousal; time to complete about 5-10 minutes) as the DSM-IV PTSD conceptualization does not represent current understanding of PTSD in the field, as current diagnostic and treatment guidelines are based on DSM-5 and ICD-10/ 11 criteria. The items range from "not at all" (1) to "always" (4) (possible range: 8-32). The RATS shows good psychometric properties with Cronbach's alpha ranging from 0.81 to 0.93 across the different languages (19). In this study, Cronbach's alpha was acceptable to good (M1: $a=$ .77; M2: $a=.83 ; M 3: a=.84)$. There is no information on clinical cut-offs and clinically significant change yet, as this was not specifically addressed in the validation study (19) of the measure and this study used a new ICD-11 conceptualization. The measure is available free of charge upon request from the authors.

\section{Traumatic Experiences}

The "Stressful Live Events questionnaire (SLE)" (20) is a self-report measure assessing 10 different potentially traumatic events at three time points: pre-migration, peri-migration and since the arrival to the current host country. The Cronbach's alpha in this sample (for M1, M2, M3) was acceptable to good, but trauma in current host-country at M3 $(a=.451)$.

\section{Daily Stressors}

The "Daily Stressors Scale for Young Refugees (DSSYR)" (21) is a self-report measure consisting of 20 potential daily stressors (1 open question for other daily stressor) assessing to what extent these have been experienced during the past month on a 4-point Likert scale ranging from "never" (1) to "always" (4) (possible range: 20-80). The questionnaire was developed on the basis of the Columbia Impairment Scale (CIS), the Adolescents Complex Daily Stressors Scale (ACDSS), and the authors' own experiences in the

field. Although this questionnaire is widely used in UYR literature, the validation study of this measure has not yet been published. The Cronbach's alpha was acceptable to good (M1: $a=.75 ; M 2: a=.80 ; M 3: a=$ .88).

\section{Statistical Analysis}

Descriptive statistics were conducted (using SPSS 26 and R Studio) to describe socio-demographic characteristics, the prevalence of traumatic events (pre- and peri-migration), daily stressors and PTSD symptoms (M1-M3). Sum scores of traumatic experiences (pre- and peri-migration; SLE), PTSD (RATS) and daily stressors (DSSYR) were conducted by calculating mean scores and multiplying this with the number of items to also receive a sum score of participants who have missing items. For the perimigration trauma load score the different time points "on my way here" and "since arrival to this country" were combined. Missing data was replaced by employing multiple imputation with five imputed datasets. The data were then analyzed via growth curve modelling (GCM) (22) to estimate inter-individual variability in intra-individual patterns of change over time. GCM can handle missing data and unequally 
spaced time points, as well as time-varying co-variates especially well. We applied a structural equation model (SEM) framework to the models. In the first unconditional model, we included the three dependent time-variant variables (PTSD, peri-migration trauma load, daily stressors) to investigate the longitudinal trajectories of the three concepts over time. In the second model with only PTSD as outcome variable, we added the time invariant factors gender and pre-migration trauma (M1) as potential predictors of the outcome over time and study country as a control variable. The third model adds to model 2 the two-time variant factors peri-migration trauma (M1-M3) and daily stressors (M1-M3). For all GCM analysis $n=3$ participants were not included due to missing RATS scores at M1. The GCM analyses were run with the R packages lavaan 0.6-8.1604 (23) and semTools 0.5-3.910 (24).

\section{Results}

\section{Traumatic Experiences}

The different traumatic experiences per subsample (study country) and total study sample are depicted in Table 2. There were high prevalence rates of traumatic experiences across all samples, ranging from $29.5-91.9 \%$. Among the least frequently reported events were sexual violence $(n=54 ; 29.5 \%)$ and forced separation from family $(n=90 ; 48.9 \%)$. Notably, the sample in Italy reported considerably more sexual violence (46.9\%) compared with the other samples (17.3-25\%). The high rate of sexual violence in the Italian sample can be explained by the inclusion of a small study sub-sample of Nigerian females who had experienced sex trafficking, though. Most often reported across samples were witnessing $(n=171$; 91.9\%) and experiencing ( $n=158 ; 84.9 \%)$ physical violence, as well as other stressful events with great danger $(n=165 ; 91.2 \%)$. Most common events in the home country were drastic changes in the family ( $n$ $=120 ; 64.8 \%)$ and other very stressful life events with great danger $(n=83 ; 45.9 \%)$. Most frequent events for "on the way to this country" were witnessing physical violence $(n=121 ; 65 \%)$ and other stressful life event with great danger $(n=114 ; 63.1 \%)$. Lastly, most often reported events since arrival to the current host country were the experience of physical violence $(n=30 ; 16.1 \%)$, drastic changes in the family ( $n=$ $27 ; 14.5 \%)$, and detention/ imprisonment $(n=27 ; 14.5 \%)$. The range in reported traumatic events was similarly high across study countries. The sample in Italy reported highest prevalence rates in eight events, compared with three events in the sample in Belgium and none in the sample in Greece.

Table 2 Traumatic experiences/ stressful life events across samples and location of event at baseline (M1) 


\section{Italy Belgium Greece}

Drastic changes in family $\mathrm{n}(\%)$

Not experienced

23

(35.9)

8 (10.4)

7

(15.9)

In my home country

$\begin{array}{llll}27 & 62 & 31 & 120 \\ (42.1) & (80.5) & (70.4) & (64.8)\end{array}$

On my way to this country

$\begin{array}{llll}6(9.4) & 8(10.4) & 10 & 24(12.9) \\ & & (22.7)\end{array}$

Since arrival in this country/place

13

(20.3)

$3(3.9) \quad 11$

41

(64.1)

Total

$(64.1) \quad(89.6) \quad(84.1) \quad(79.5)$

Forced separation from family $\mathrm{n}(\%)$

Not experienced

46

(71.9)

(25)

$27(14.5)$

In my home country

10

$\begin{array}{ll}10 & 48 \\ (15.7) & (63.1)\end{array}$

On my way to this country

9

(14.1)

Since arrival in this country/place

$1(1.6)$

Total

$\begin{array}{llll}18 & 54 & 18 & 90(48.9) \\ (28.1) & (71.1) & (40.9) & \end{array}$

War or armed military conflict $\mathrm{n}(\%)$

Not experienced

In my home country

$\begin{array}{llll}20 & 26 & 19 & 65(34.9) \\ (31.1) & (33.3) & (43.2) & \\ 15 & 46(59) & \begin{array}{l}23 \\ (52.3)\end{array} & 84(45.2) \\ (23.4) & & & \\ 37 & 8(10.3) & \begin{array}{l}9 \\ (20.4)\end{array} & 54(29.1) \\ (57.8) & & 3(6.8) & 3(1.6) \\ - & -- & 5 & 121 \\ 44 & 52 & 25 & (65.1) \\ (68.8) & (66.7) & (56.8) & (65 .)\end{array}$

Forced to work n (\%)

Not experienced

21

(33.3)
$30(39)$

$$
24
$$

$94(51.1)$

$71(38.5)$

$21(11.3)$

$8(4.3)$

$90(48.9)$ 


\begin{tabular}{|c|c|c|c|c|}
\hline In my home country & $4(6.4)$ & $\begin{array}{l}18 \\
(23.4)\end{array}$ & $\begin{array}{l}15 \\
(34.9)\end{array}$ & $37(20.1)$ \\
\hline On my way to this country & $\begin{array}{l}31 \\
(49.2)\end{array}$ & $30(39)$ & $\begin{array}{l}5 \\
(11.6)\end{array}$ & $66(36)$ \\
\hline Since arrival in this country/place & $\begin{array}{l}11 \\
(17.5)\end{array}$ & $2(2.6)$ & $3(7)$ & $16(8.7)$ \\
\hline Total & $\begin{array}{l}42 \\
(66.7)\end{array}$ & $47(61)$ & $\begin{array}{l}19 \\
(44.2)\end{array}$ & $108(59)$ \\
\hline \multicolumn{5}{|l|}{ Experienced physical violence $\mathrm{n}(\%)$} \\
\hline Not experienced & $\begin{array}{l}7 \\
(11.1)\end{array}$ & $\begin{array}{l}13 \\
(16.5)\end{array}$ & $\begin{array}{l}8 \\
(18.2)\end{array}$ & $28(15.1)$ \\
\hline In my home country & $\begin{array}{l}14 \\
(22.2)\end{array}$ & $\begin{array}{l}34 \\
(43.14)\end{array}$ & $\begin{array}{l}23 \\
(52.2)\end{array}$ & $71(38.2)$ \\
\hline On my way to this country & $\begin{array}{l}44 \\
(69.8)\end{array}$ & $\begin{array}{l}48 \\
(60.8)\end{array}$ & $\begin{array}{l}21 \\
(47.7)\end{array}$ & $\begin{array}{l}113 \\
(60.7)\end{array}$ \\
\hline Since arrival in this country/place & $\begin{array}{l}15 \\
(23.7)\end{array}$ & $1(1.3)$ & $\begin{array}{l}14 \\
(31.8)\end{array}$ & $30(16.1)$ \\
\hline Total & $\begin{array}{l}56 \\
(88.9)\end{array}$ & $\begin{array}{l}66 \\
(83.5)\end{array}$ & $\begin{array}{l}36 \\
(81.8)\end{array}$ & $\begin{array}{l}158 \\
(84.9)\end{array}$ \\
\hline \multicolumn{5}{|l|}{ Witnessed physical violence $\mathrm{n}(\%)$} \\
\hline Not experienced & $3(4.7)$ & $6(7.7)$ & $\begin{array}{l}6 \\
(13.6)\end{array}$ & $15(8.1)$ \\
\hline In my home country & $\begin{array}{l}14 \\
(21.8)\end{array}$ & $\begin{array}{l}45 \\
(57.7)\end{array}$ & $\begin{array}{l}24 \\
(54.4)\end{array}$ & $83(44.7)$ \\
\hline On my way to this country & $\begin{array}{l}54 \\
(83.4)\end{array}$ & $\begin{array}{l}45 \\
(57.7)\end{array}$ & $\begin{array}{l}22 \\
(49.9)\end{array}$ & $121(65)$ \\
\hline Since arrival in this country/place & $5(7.8)$ & - & $\begin{array}{l}16 \\
(36.3)\end{array}$ & $21(11.3)$ \\
\hline Total & $\begin{array}{l}61 \\
(95.3)\end{array}$ & $\begin{array}{l}72 \\
(92.3)\end{array}$ & $\begin{array}{l}38 \\
(86.4)\end{array}$ & $\begin{array}{l}171 \\
(91.9)\end{array}$ \\
\hline \multicolumn{5}{|l|}{ Experienced sexual violence $\mathrm{n}(\%)$} \\
\hline Not experienced & $\begin{array}{l}34 \\
(53.1)\end{array}$ & $\begin{array}{l}62 \\
(82.7)\end{array}$ & $\begin{array}{l}33 \\
(75)\end{array}$ & $\begin{array}{l}129 \\
(70.5)\end{array}$ \\
\hline In my home country & $4(6.3)$ & $5(6.6)$ & $\begin{array}{l}6 \\
(13.6)\end{array}$ & $15(8.1)$ \\
\hline On my way to this country & $\begin{array}{l}26 \\
(40.6)\end{array}$ & $9(12)$ & $4(9.1)$ & $39(21.2)$ \\
\hline Since arrival in this country/place & $\begin{array}{l}8 \\
(12.5)\end{array}$ & - & $\begin{array}{l}5 \\
(11.4)\end{array}$ & $13(7)$ \\
\hline
\end{tabular}




\begin{tabular}{|c|c|c|c|c|}
\hline Total n (\%) & $\begin{array}{l}30 \\
(46.9)\end{array}$ & $\begin{array}{l}13 \\
(17.3)\end{array}$ & $\begin{array}{l}11 \\
(25)\end{array}$ & $54(29.5)$ \\
\hline \multicolumn{5}{|l|}{ Detention or imprisonment n (\%) } \\
\hline Not experienced & $\begin{array}{l}12 \\
(18.8)\end{array}$ & $\begin{array}{l}18 \\
(23.1)\end{array}$ & $\begin{array}{l}11 \\
(25)\end{array}$ & $41(22)$ \\
\hline In my home country & $9(14)$ & $\begin{array}{l}18 \\
(23.1)\end{array}$ & $7(16)$ & $34(18.3)$ \\
\hline On my way to this country & $\begin{array}{l}49 \\
(76.5)\end{array}$ & $\begin{array}{l}49 \\
(62.8)\end{array}$ & $\begin{array}{l}13 \\
(29.6)\end{array}$ & $\begin{array}{l}111 \\
(59.7)\end{array}$ \\
\hline Since arrival in this country/place & $6(9.4)$ & $3(3.8)$ & $\begin{array}{l}18 \\
(40.9)\end{array}$ & $27(14.5)$ \\
\hline Total & $\begin{array}{l}52 \\
(81.3)\end{array}$ & $\begin{array}{l}60 \\
(76.9)\end{array}$ & $\begin{array}{l}33 \\
(75)\end{array}$ & $145(78)$ \\
\hline \multicolumn{5}{|c|}{ Other very stressful life event with great danger $\mathrm{n}(\%)$} \\
\hline Not experienced & $\begin{array}{l}7 \\
(11.9)\end{array}$ & $4(5.1)$ & $\begin{array}{l}5 \\
(11.4)\end{array}$ & $16(8.8)$ \\
\hline In my home country & $\begin{array}{l}9 \\
(15.3)\end{array}$ & $\begin{array}{l}50 \\
(64.1)\end{array}$ & $\begin{array}{l}24 \\
(54.6)\end{array}$ & $83(45.9)$ \\
\hline On my way to this country & $\begin{array}{l}45 \\
(76.3)\end{array}$ & $\begin{array}{l}42 \\
(53.9)\end{array}$ & $\begin{array}{l}27 \\
(61.4)\end{array}$ & $\begin{array}{l}114 \\
(63.1)\end{array}$ \\
\hline Since arrival in this country/place & $\begin{array}{l}14 \\
(23.8)\end{array}$ & - & $\begin{array}{l}11 \\
(25.1)\end{array}$ & $25(13.9)$ \\
\hline Total & $\begin{array}{l}52 \\
(88.1)\end{array}$ & $\begin{array}{l}74 \\
(94.9)\end{array}$ & $\begin{array}{l}39 \\
(88.6)\end{array}$ & $\begin{array}{l}165 \\
(91.2)\end{array}$ \\
\hline \multicolumn{5}{|c|}{$\begin{array}{l}\text { Other very stressful life event with someone else in great } \\
\text { danger } n(\%)\end{array}$} \\
\hline Not experienced & $\begin{array}{l}10 \\
(16.4)\end{array}$ & $\begin{array}{l}13 \\
(16.7)\end{array}$ & $\begin{array}{l}8 \\
(18.6)\end{array}$ & $31(17)$ \\
\hline In my home country & $\begin{array}{l}7 \\
(11.5)\end{array}$ & $\begin{array}{l}38 \\
(48.7)\end{array}$ & $\begin{array}{l}19 \\
(44.3)\end{array}$ & $64(35.2)$ \\
\hline On my way to this country & $\begin{array}{l}45 \\
(73.8)\end{array}$ & $\begin{array}{l}36 \\
(46.1)\end{array}$ & $\begin{array}{l}23 \\
(53.6)\end{array}$ & $\begin{array}{l}104 \\
(57.1)\end{array}$ \\
\hline Since arrival in this country/place & $5(8.2)$ & $1(1.3)$ & $\begin{array}{l}14 \\
(32.7)\end{array}$ & $20(10.9)$ \\
\hline Total & $\begin{array}{l}51 \\
(83.6)\end{array}$ & $\begin{array}{l}65 \\
(83.3)\end{array}$ & $\begin{array}{l}35 \\
(81.4)\end{array}$ & $151(83)$ \\
\hline
\end{tabular}


Legend. Total means number of participants who report the event independent of location. The \% value is valid percent for each subsample and time point.

\section{Unconditional growth models}

Table 3 presents the means, standard deviations and range of pre- and peri-migration trauma, PTSD, and daily stressors. The models provided good model fit for $\operatorname{PTSD}\left(X^{2}(1)=0.3612, p=.569, C F I=1.000\right.$, $S R M R=0.0120, R M S E A=0.000)$, peri-migration trauma $\left(\chi^{2}(1)=2.98875, \mathrm{p}=.150, C F I=0.96050, S R M R=\right.$ $0.03800, R M S E A=0.09750)$, and daily stressors $\left(\chi^{2}(1)=0.9820, \mathrm{p}=.388, C F I=0.9968, S R M R=0.0172\right.$, $R M S E A=0.0278$ ). For results of the unconditional growth models on peri-migration trauma, PTSD, and daily stressors, please see Table 4 and Figures 1A - C. PTSD scores significantly decreased over time. There was no significant variance at $\mathrm{T} 1$ between the individuals, meaning that there is no significant differences between the respondents at $\mathrm{T} 1(t(206,479)=1.54 ; p=.125)$. The evolution over time also did not differ significantly between the individuals $(t(22.35)=.87 ; p=.396)$. The covariance between intercept and slope $(\beta=1.0, S E=2.97)$ was not significant $(t(51.60)=0.34 ; p=.739)$. The peri-migration score decreased, but not significantly, over time.

There was a significant variance at T1 between the individuals $(t(184.92)=3.53 ; p<.001)$, the evolution over time also did not differ significantly between the individuals $(t(9.81)=1.05 ; p=.321)$. The covariance between intercept and slope $(\beta=-2.35, S E=1.03)$ was significant $(t(24.19)=-2.27 ; p=.033)$, which means that the intercept affected the slope. The daily stressor score significantly decreased over time. The variance varied significantly between individuals at T1 $(t(8.94)=3.03 ; p=.014)$, the variance in the slope didn't vary between individuals $(t(6.30)=1.89 ; p=.105)$, though. The covariance between intercept and slope $(\beta=-24.43, S E=15.23)$ was not significant $(t(6.20)=-1.60 ; p=.158)$.

Table 3 Descriptive data on pre- and peri-migration trauma, daily stressors and PTSD across all measurement time points (M1-M3) $(N=187)$

\begin{tabular}{|llll|}
\hline & M1 & M2 & M3 \\
& M (SD), range & M (SD), range & M (SD), range \\
\hline Pre-migration trauma & $3.53(2.55), 0-9$ & $\mathrm{n} / \mathrm{a}$ & $\mathrm{n} / \mathrm{a}$ \\
\hline Peri-migration trauma & $4.80(2.59), 0-10$ & $4.50(2.71), 0-10$ & $4.50(5.10), 0-9$ \\
\hline Daily stressors & $38.78(9.00), 25-67$ & $35.76(9.37), 21-61$ & $34.50(10.80), 20-66$ \\
\hline PTSD symptoms & $20.10(5.28), 9-32$ & $18.93(5.77), 8-32$ & $17.74(5.61), 8-32$ \\
\hline $\begin{array}{l}\text { Note. n/a indicates no data available. Since all participants were on the move during the study, } \\
\text { traumatic events prior migration (pre-migration) are only reported at baseline. M1 = baseline; M2 = 6- } \\
\text { 12 month follow-up; M3 = 18-24 month follow-up; PTSD = posttraumatic stress disorder. }\end{array}$ \\
\hline
\end{tabular}

Table 4 Unstandardized estimates and standard errors of means and variances or parameters of unconditional growth models 


\begin{tabular}{|llllllll|}
\hline & Intercepts & \multicolumn{7}{c|}{ Variance } \\
\hline & Estimate & SE & $\mathrm{p}$ & Estimate & SE & $\mathrm{p}$ \\
\hline PTSD symptoms Intercept & 19.83 & 0.50 & $<.001$ & 8.21 & 5.33 & .125 \\
\hline PTSD symptoms Slope & -0.87 & 0.31 & .014 & 2.43 & 2.81 & .396 \\
\hline Peri-migration trauma Intercept & 4.90 & 0.28 & $<.001$ & 6.21 & 1.76 & $<.001$ \\
\hline Peri-migration trauma Slope & -0.17 & 0.16 & .325 & 0.77 & 0.74 & .321 \\
\hline Daily stressors Intercept & 42.35 & 1.29 & $<.001$ & 83.94 & 27.69 & .014 \\
\hline Daily stressors Slope & -2.64 & 0.77 & .002 & 23.280 & 12.30 & .105 \\
\hline
\end{tabular}

\section{Conditional growth curve model}

The first model on only time-invariant predictors (gender, study country and pre-migration trauma) fit the data well: $(X 2(4)=8.46600, p=.180, C F I=.95225, S R M R=.03800, R M S E A=0.07250)$. Subsequently, we added the time-variant factors (peri-migration trauma, daily stressors) which resulted in an insufficient model fit $(X 2(17)=88.6614, p=<.001, C F I=.7220, S R M R=0.0628, R M S E A=0.1630)$. This means these results should be interpreted with caution. Please see Table 5 and Figures $1 \mathrm{D}-\mathrm{E}$ for the results of the model. There was no significant effect of the control variable study country, neither at baseline nor on the longitudinal trajectory of PTSD. The slope was marginally significantly lower in the sample in Italy than in the sample in Belgium, though. Females reported higher PTSD compared with male participants at baseline, but gender did not influence the longitudinal trajectory of PTSD over time. The pre-migration trauma load also had a significant effect on PTSD at baseline, but not on the longitudinal trajectory of PTSD. Peri-migration trauma load had no significant effect on PTSD at any time point, however, there was a marginally significant effect of peri-traumatic load at M3 on PTSD. The daily stressors had a significant impact on PTSD on all three time points, meaning that the more daily stressors, the higher PTSD symptom burden. This effect became stronger over time.

Table 5 Standardized estimates of the time-invariant (study country, gender, peri-migration trauma (M1) and time-invariant (peri-migration trauma M1-M3, daily stressors M1-M3) coefficients and growth parameters of PTSD $(n=185)$. 


\begin{tabular}{lllllll} 
& intercept & \multicolumn{7}{c}{ slope } \\
& Estimate & SE & p & Estimate & SE & p \\
\hline Country (Greece)* & -1.33 & 1.68 & .430 & -0.43 & 1.04 & .683 \\
\hline Country (Italy)* & .48 & 1.70 & .778 & -1.83 & 1.03 & .082 \\
\hline Gender (male)** & -4.61 & 1.70 & .007 & 0.93 & 1.02 & .438 \\
\hline Pre-migration trauma & .53 & .28 & .069 & -0.17 & 0.17 & .332 \\
\hline Peri-migration trauma M1 &.. &.. &.. & -.02 & 0.25 & .945 \\
\hline Peri-migration trauma M2 &.. &.. &.. & 0.32 & 0.21 & .137 \\
\hline Peri-migration trauma M2 &.. &.. &.. & -0.18 & 0.19 & .407 \\
\hline Daily stressors M1 &.. &.. &.. & 0.11 & 0.06 & .065 \\
\hline Daily stressors M2 &.. &.. &.. & 0.15 & 0.04 & .001 \\
\hline Daily stressors M3 &.. &.. &.. & 0.28 & 0.05 & .001 \\
\hline
\end{tabular}

Note. *reference group is Belgium; ** reference group is female

\section{Discussion}

This is the first study that investigates trauma, daily stressors and PTSD in a cross-country sample longitudinally with UYRs who are currently on the move. Results of this study revealed a dramatically high trauma load pre- and peri-migration across all UYR sub-samples. Especially interpersonal trauma, such as witnessing and experiencing physical violence, is common with almost all UYRs reporting this at any time point during their flight, or in their home country. Even the least frequent events (sexual violence and forced separation from family) were reported by at least one-third of the participants, which is alarming. This study extends the growing body of research on cumulative trauma in UYRs by demonstrating the high trauma load in a heterogeneous and representative sample of UYRs on the move across different study settings (e.g. refugee camps, detention, or asylum centers), regions and countries in Europe.

Contrary to longitudinal studies with settled UYRs in Norway (11) and Belgium (6) which showed that PTSD remained stable in the course of 6,12 , and 18 months post-arrival to the host country, results of this study suggest a significant decrease of PTSD symptoms over time. A recent follow-up study with $n=$ 72 asylum-seeking children and adolescents who settled in Germany (16) report overall symptom decrease in PTSD at 12-month follow-up, but highlight the fact that $37.5 \%$ still reported clinically significant symptoms. The results of our study don't allow conclusions on clinically relevant PTSD scores, but sum scores are across all time points in the upper midfield which suggests that, similarly to the study by Müller et al. (16), PTSD scores slightly decrease but are dramatically elevated throughout the 27 months of study conduction. 
In line with numerous studies on risk factors for PTSD development in UYRs (3), this study also showed that female gender was associated with higher PTSD at baseline with a similar longitudinal PTSD trajectory. Results indicate that the higher the pre-migration trauma load, the higher was the baseline PTSD score which is in line with the assumption of the dose-response model in which an individual's risk of response varies with the magnitude of the stressors (25). This effect was also found in numerous studies on UYRs' PTSD levels (3). However, peri-migration trauma had no effect on PTSD scores, neither at baseline, nor across time. As the number of traumatic events was especially high peri-migration, a ceiling effect could be one explanation of this result. Another explanation might be the so-called buildingblock effect in severely traumatized samples (26). This effect which similarly to the dose-response effect, highlights the cumulative damaging effect of multiple traumatic events on mental health, suggests that each individual suffering from ongoing severe traumatization has a so called "psychobiological breaking point". Once this state has been reached, subsequent traumatic events don't create further impact on symptoms. As many participants in this study find themselves in precarious and potentially traumatizing situations, such as the living conditions in refugee camps in Greece, the explanation of a psychobiological breaking point seems all the more evident.

In addition to the high symptom burden in relation to cumulative traumatization, the results of this study strongly indicate that daily stressors have a significant impact on PTSD in UYRs, as already suggested in other studies with accompanied and unaccompanied refugee minors $(11,27)$. This data therefore contributed to the ongoing discussion on the interplay between trauma and daily stressors, and their combined effect on mental health by several scholars. The results of this study support recent research which advocates a more ecological approach of refugee distress. A recent framework by Miller and Rasmussen (28) highlights, for example, that mental health stems not only from prior trauma/war exposure, but also from ongoing and/or displacement-related stressors. Moreover, being on the move with continuous stressful life events often goes hand in hand with an ongoing sense of threat. The cognitive model of trauma and PTSD by Ehlers and Clark (27) indicates that the subjective appraisal of the event and current situation (such as sense of threat) has a crucial impact on the development and chronification of symptoms. Future research needs to focus on refugees' experienced sense of threat and related factors, such as available coping strategies during their flight, in order to better understand the emotional and cognitive risk factors in the development of mental health issues in the long run (29).

\section{Limitations}

Although this study has many strengths, such as the implementation of an interview format, the longitudinal study design and multi-country context, the translation of the questionnaires and the presence of interpreters during assessment, several limitations which could limit generalizability of these findings need to be addressed. First, the study comprises a very heterogeneous and representative, but rather small sample for the chosen analysis which could have resulted in insufficient model fit of the last GCM Model. Second, some participants could be considered "settled" rather than being "on the move" as they had the intention to stay in the country, particularly in the Belgian sample. Acknowledging that settlement is a subjectively and objectively complex process that is described with numerous definitions 
in literature, we chose to refer to the entire sample as "on the move" to reflect the dynamic migration context. Moreover, all participants had in fact recently moved. Third, although the measure DSSYR has been widely used in the field of refugee mental health (11), it might not fully capture the diversified stressors faced by the participants in each setting, and the measure is still not validated in its current form. However, a recent validation study by the authors is in preparation for submission. Fourth, as daily stressors and traumatic events were assessed via checklists and treated as sum scores in the analysis, which is a common approach in the field, potentially crucial characteristics of the events, such as their intensity, frequency, or duration, are neglected and thus results might to some extent be biased and oversimplified. Fifth, all measures in this study were developed in western societies which might entail transcultural errors due to the various cultural contexts of the participants. Sixth, this study focused on several specific risk factors and their relation to PTSD symptoms, and thus neglects other potential risk factors and trauma-related mental health areas which are relevant for UYRs. Future studies need to replicate these findings in UYRs on the move and further investigate known protective and risk factors for the development of mental health issues (such as social support) on the one hand, and other mental health areas, but also important aspects such as resiliency, function, and quality of life on the other hand. Seventh, as the large majority of the study was male, findings on gender effects have to be interpreted with caution.

\section{Conclusion}

In sum, the results of this longitudinal multi-site and multi-country study highlight the high rates of traumatization pre- and peri-migration, the detrimental effect of daily stressors on the flight and the alarmingly high rates of PTSD in this representative sample of UYRs on the move. Humanitarian assistance and a well-being centered political intervention is urgently needed to curb the oftentimes inhumane and threatening conditions they face during their journey, with structured protection, medical, and psychological support. Especially UYRs who are in an important phase of their emotional, cognitive, and social development lack social support, and family guidance which are known protective factors. It is highly important to prioritize actions aimed at reinforcing the child protection system along all migratory routes.

\section{Declarations}

\section{Ethics approval and consent to participate}

All participants and, if already appointed, their legal guardians in the case of minors gave their informed written consent before being enrolled in the study. The study protocol was approved by the institutional review board (IRB) at Ghent University (\#2017-23-Ine Lietaert).

\section{Consent for publication}


The consent for publication was obtained from all study participants. The individual information was handled anonymous and no images or videos were employed.

\section{Availability of data and material}

For privacy reasons the data is not fully available online. Proposals should be directed to ilse.derluyn@ugent.be; to gain access, data requestors will need to sign a data access agreement.

\section{Competing Interest}

There are no competing interests.

\section{Funding}

This work was supported by the European Research Council under a HORIZON Grant (714222) and the Deutsche Forschungsgemeinschaft (DFG, German Research Foundation; 447787115.

\section{Author Contributions}

All authors contributed to the conceptualization of the study design and interpretation of the results. MB, SA, MR, and OR mainly collected the data, EP and ID were mainly involved in data analysis. All authors critically reviewed important intellectual content, approved the final version of this submission and agree to be accountable for all aspects of the work in ensuring that questions related to the accuracy or integrity of any part of the work are appropriately investigated and resolved.

\section{Acknowledgements}

European Research Council [HORIZON project number: 714222] and Deutsche Forschungsgemeinschaft (DFG, German Research Foundation) - 447787115. All authors confirm that they had full access to all the data in the study and accept responsibility to submit for publication.

\section{References}

1. UNHCR. Figures at a Glance [Internet]. 2020. Available from: https://www.unhcr.org/figures-at-aglance.html

2. UNHCR. Refugee Data Finder [Internet]. Available from: https://www.unhcr.org/refugeestatistics/download/?url=QBtmr4

3. Scharpf F, Kaltenbach E, Nickerson A, Hecker T. A systematic review of socio-ecological factors contributing to risk and protection of the mental health of refugee children and adolescents. Clin Psychol Rev. 2020;83:1019-30.

4. Farhat JB, Blanchet K, Bjertrup PJ, Veizis A, Perrin C, Coulborn RM, et al. Syrian refugees in Greece: experience with violence, mental health status, and access to information during the journey and while in 
Greece. BMC Med. 2018;16(1):1-12.

5. Jud A, Pfeiffer E, Jarczok M. Epidemiology of violence against children in migration: a systematic literature review. Child Abuse Negl. 2020;108:104634.

6. Vervliet M, Lammertyn J, Broekaert E, Derluyn I. Longitudinal follow-up of the mental health of unaccompanied refugee minors. Eur Child Adolesc Psychiatry. 2014;23(5):337-46.

7. Jensen TK, Fjermestad KW, Granly L, Wilhelmsen NH. Stressful life experiences and mental health problems among unaccompanied asylum-seeking children. Clin Child Psychol Psychiatry. 2015;20(1):106-16.

8. Kien C, Sommer I, Faustmann A, Gibson L, Schneider M, Krczal E, et al. Prevalence of mental disorders in young refugees and asylum seekers in European Countries: a systematic review. Eur Child Adolesc Psychiatry [Internet]. 2019;28(10):1295-310. Available from: https://doi.org/10.1007/s00787-018-1215-z

9. Blackmore R, Boyle JA, Fazel M, Ranasinha S, Gray KM, Fitzgerald G, et al. The prevalence of mental illness in refugees and asylum seekers: a systematic review and meta-analysis. PLoS Med. 2020;17(9):e1003337.

10. Bean T, Derluyn I, Eurelings-Bontekoe E, Broekaert E, Spinhoven P. Comparing psychological distress, traumatic stress reactions, and experiences of unaccompanied refugee minors with experiences of adolescents accompanied by parents. J Nerv Ment Dis. 2007;195(4):288-97.

11. Jensen TK, Skar AMS, Andersson ES, Birkeland MS. Long-term mental health in unaccompanied refugee minors: pre-and post-flight predictors. Eur Child Adolesc Psychiatry. 2019;28(12):1671-82.

12. Reed R V., Fazel M, Jones L, Panter-Brick C, Stein A. Mental health of displaced and refugee children resettled in low-income and middle-income countries: risk and protective factors. Lancet. 2012;379(9812):250-65.

13. Operational Portal Refugee Situation. Mediteranien Situation [Internet]. Available from: https://data2.unhcr.org/en/situations/mediterranean

14. Stathopoulou T, Avrami L, Kostaki A, Cavounidis J, Eikemo TA. Safety, health and trauma among newly arrived refugees in Greece. J Refug Stud. 2019;32(Special_Issue_1):i22-35.

15. Rodolico A, Vaccino N, Riso MC, Concerto C, Aguglia E, Signorelli MS. Prevalence of post-traumatic stress disorder among asylum seekers in Italy: a population-based survey in Sicily. J Immigr Minor Heal. $2019 ; 1-5$.

16. Müller LRF, Gossmann K, Hartmann F, Büter KP, Rosner R, Unterhitzenberger J. 1-year follow-up of the mental health and stress factors in asylum-seeking children and adolescents resettled in Germany. BMC Public Health. 2019;19(1):1-11. 
17. Jensen TK, Fjermestad KW, Granly L, Wilhelmsen NH. Stressful life experiences and mental health problems among unaccompanied asylum-seeking children. Clin Child Psychol Psychiatry. 2015;20(1):106-16.

18. Pfeiffer E, Sachser C, Rohlmann F, Goldbeck L. Effectiveness of a trauma-focused group intervention for young refugees: a randomized controlled trial. J Child Psychol Psychiatry Allied Discip. 2018;59(11):1171-9.

19. Bean T, Derluyn I, Eurelings-Bontekoe E, Broekaert E, Spinhoven P. Validation of the multiple language versions of the Reactions of Adolescents to Traumatic Stress questionnaire. J Trauma Stress Off Publ Int Soc Trauma Stress Stud. 2006;19(2):241-55.

20. Bean T, Eurelings-Bontekoe EHM, Derluyn I, Spinhoven P. SLE User's Manual. Oegstgeest. 2004.

21. Vervliet M, Broerkeart E, Derluyn I. Daily Stressors Scale for Young Refugees (DSSYR). 2010.

22. Bryk AS, Raudenbush SW. Hierarchical linear models: Applications and data analysis methods. Sage Publications, Inc. Sage Publications, Inc. 1992.

23. Rosseel Y. lavaan: An R Package for Structural Equation Modeling. J Stat Softw. 2012;48(2):1-36.

24. Jorgensen TD, Pornprasertmanit S, Schoemann AM, Rosseel Y. semTools: Useful tools for structural equation modeling. R package version 0.5-4. 2021.

25. Wyler AR, Masuda M, Holmes TH. Magnitude of life events and seriousness of illness. Psychosom Med. 1971;

26. Schauer M, Neuner F, Karunakara U, Klaschik C, Robert C, Elbert T. PTSD and the building block effect of psychological trauma among West Nile Africans. Eur Soc Trauma Stress Stud Bull. 2003;10(2):5-6.

27. Ehlers A, Clark DM. A cognitive model of posttraumatic stress disorder. Behav Res Ther. 2000;38:31945 .

28. Miller KE, Rasmussen A. The mental health of civilians displaced by armed conflict: an ecological model of refugee distress. Epidemiol Psychiatr Sci. 2017;26(2):129-38.

29. Javanbakht A, Grasser LR, Kim S, Arfken CL, Nugent N. Perceived health, adversity, and posttraumatic stress disorder in Syrian and Iraqi refugees. Int J Soc Psychiatry. 2020;

\section{Figures}



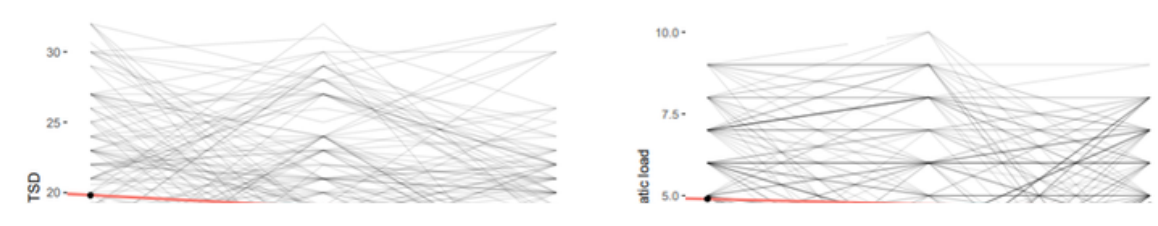

in.

\section{Figure 1}

A. Evolution of posttraumatic stress disorder (PTSD) over time.

B. Evolution of peri-migration trauma over time.

C. Evolution of daily stressors over time.

D. The effect of gender (female vs. gender) on posttraumatic stress disorder (PTSD) over time.

$\boldsymbol{E}$. The effect of study country on posttraumatic stress disorder (PTSD) over time.

Note. The three measurement time points were 1 =baseline, $2=$ approximately 8 months post baseline and 3 = approximately 21 months post baseline.

\section{Supplementary Files}

This is a list of supplementary files associated with this preprint. Click to download.

- OnlineSupplementSP1.docx 